\title{
EL FENÓMENO MIGRATORIO ENTRE ANDALUCÍA Y MARRUECOS: REFLEXIONES PARA UN DESARROLLO HUMANO ENTRE AMBAS ORILLAS
}

\author{
MIGRATION PHENOMENON BETWEEN ANDALUSIA AND MOROCCO: \\ REFLECTIONS FOR HUMAN DEVELOPMENT BETWEEN THE TWO \\ SHORES
}

\author{
Jamal Benamar \\ Universidad Abdelmalek Essaãdi de Tánger-Tetuán. Marruecos/Morocco \\ byamal2000@yahoo.fr \\ Noelia Melero Aguilar \\ Universidad de Sevilla. España/Spain \\ nmelero@us.es
}

Recibido/Received: 15/05/2015

Modificado/Modified: 17/08/2015

Aceptado/Accepted: 18/09/2015

\section{RESUMEN}

Las llamadas migraciones irregulares, clandestinas o ilegales, que se están desarrollando en la última década, adquieren una singular importancia en el espacio mediterráneo, especialmente entre España y Marruecos. En este marco, este trabajo son las conclusiones de un estudio que recoge las impresiones y valoraciones de expertos españoles y marroquíes sobre la inmigración irregular entre la frontera Sur de Europa (Andalucía Sur) y el Norte de África (Norte de Marruecos), analizando su incidencia sobre las economías, las sociedades y las políticas de los países de acogida y de origen. Las conclusiones nos acercan a aspectos como la valoración del fenómeno de la inmigración, las características de los inmigrantes, la evolución de los flujos migratorios y las posibles soluciones a esta difícil situación.

\section{PALABRAS CLAVE}

Migraciones, desarrollo humano, políticas.

\section{SUMARIO}

1. Introducción. 2. Antecedentes e incidencia de la emigración en Marruecos. 3. Metodología y métodos. 4. Resultados. 5. Conclusiones. Bibliografía.

\footnotetext{
ABSTRACT

Irregular migration, clandestine or illegal, being developed in the last decade, acquires a unique importance in the Mediterranean area, especially between Spain and Morocco. In this context, this work represents the findings of a study that collects impressions and assessments of Spanish and Moroccan experts on illegal immigration between the borders of Southern Europe (Southern Andalucía) and North Africa (Northern Morocco), analyzing their impact on the economies, societies and the policies of the host and home countries. Thus, the conclusions have drawn us closer to different aspects such as the assessment of the phenomenon of immigration, the characteristics of immigrants, development in migration flows and the possible solutions to this difficult situation.
} 


\section{KEYWORDS}

Migration, human development, policy.

\section{CONTENTS}

1. Introduction. 2. Background and incidence of migration in Morocco. 3. Methodology and Methods. 4. Results. 5. Conclusions. References.

\section{INTRODUCCIÓN}

El fenómeno de las migraciones en las últimas décadas se ha visto azotado por un elevado desplazamiento humano entre países. Según la definición de la UNESCO, las migraciones son desplazamientos de la población de una delimitación geográfica a otra por un espacio de tiempo considerable o indefinido que conlleva un cambio de entorno político-administrativo, social y/o cultural relativamente permanente en el tiempo, así como la interrupción de actividades vitales en un determinado lugar geográfico y su reorganización vital en otro (en la actualidad, más de 215 millones de personas, o el 3\% de la población mundial, vive fuera de su país de origen. Los flujos migratorios actuales, comparados con el tamaño de la población, son más reducidos que los registrados durante las últimas décadas del siglo XIX. El principal destino de migración es Estados Unidos, seguido por la Federación de Rusia, Alemania, Arabia Saudita y Canadá. Los principales países de inmigración, comparados con el tamaño de la población, son Qatar (87\%), Mónaco (72\%), los Emiratos Árabes Unidos (70\%), Kuwait (69\%) y Andorra (64\%) (Banco Mundial, 2011:3).

En este marco, los inmigrantes, protagonistas de estos procesos, se convierten en agentes activos que contribuyen significativamente al crecimiento de las economías de los países europeos y también de los países de origen.
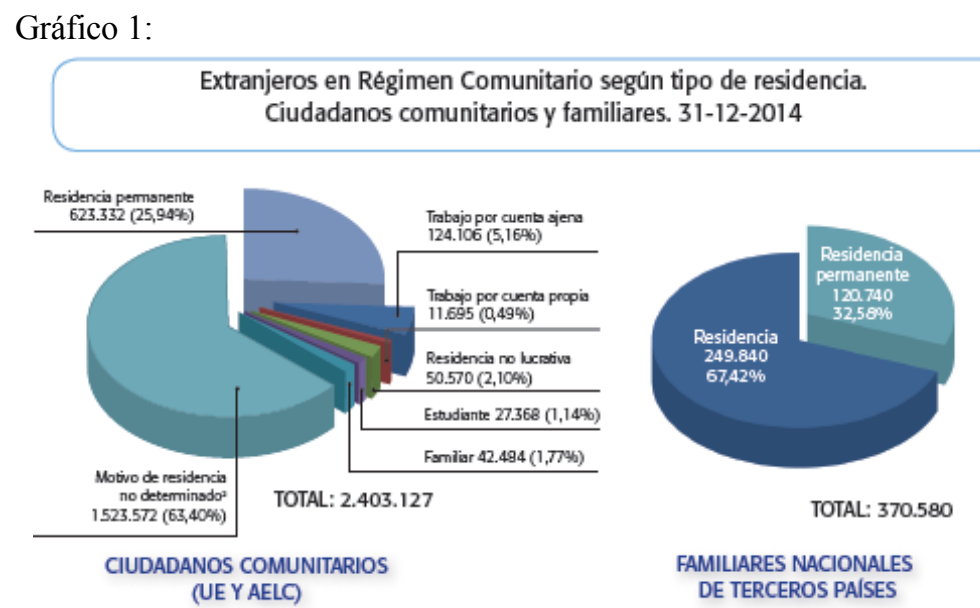

Fuente: Observatorio Permanente de la Inmigración "Extranjeros residentes en España, Principales resultados" (31 diciembre 2014).

Los diferentes informes del Observatorio Permanente de la Inmigración del Ministerio español de Empleo y Seguridad Social (OPM, 2014) indican la tendencia de crecimiento del 
número de inmigrantes extracomunitarios y nos lleva a reflexionar sobre como más allá de las connotaciones negativas que afloran en torno a este fenómeno, los flujos migratorios representan para los países europeos una fuente diversificada de riqueza (cultural, económica, social, demográfica: "Los inmigrantes han contribuido a la creación del 50\% de los nuevos empleos desde el año 2001 e ingresan 23 mil millones de euros por año a Hacienda, o sea $6,6 \%$ del presupuesto del Estado. Esta contribución seguirá creciendo en los próximos años". Según un estudio hecho público a mediados del mes de noviembre 2006 y dirigido por Miguel Sebastián, principal consejero económico del ex-jefe del Gobierno, José Luís Rodríguez Zapatero), y una alternativa para las economías de los países de origen (Sebastián, 2006: 7 y 23).

La constitución de la Organización Mundial de la Inmigración, en su preámbulo (OIM, 2014: 4), reconoce los vínculos entre la migración y el desarrollo con el precepto de que la migración internacional, si se encara adecuadamente, puede contribuir al crecimiento y a la prosperidad de los países de origen y de destino además de ser provechosa para los propios migrantes. En una era de movilidad humana sin precedentes, es particularmente apremiante fomentar una mayor comprensión de los vínculos entre la migración y el desarrollo, y adoptar medidas prácticas para acrecentar los beneficios de la migración de cara al desarrollo, además de elaborar soluciones sostenibles para situaciones migratorias problemáticas.

Tabla 1: Extranjeros con certificado, principales nacionalidades

\begin{tabular}{|c|c|c|c|c|c|}
\hline \multicolumn{6}{|c|}{$\begin{array}{c}\text { Extranjeros con certificado de registro o tarjeta de residencia. } \\
\text { Principales nacionalidades. } 31-12-2014\end{array}$} \\
\hline & \multirow{2}{*}{\multicolumn{2}{|c|}{$31-12-2014$}} & \multicolumn{3}{|c|}{ Variación (\%) } \\
\hline & & & \multirow{2}{*}{$\begin{array}{l}\text { Trimestral: } \\
\text { respecto a } \\
30-9-2014\end{array}$} & \multirow{2}{*}{$\begin{array}{c}\text { Semestral: } \\
\text { respecto a } \\
30-6-2014 \\
0,40\end{array}$} & \multirow{2}{*}{$\begin{array}{c}\text { Interanual: } \\
\text { respecto a } \\
31-12-2013 \\
0,37\end{array}$} \\
\hline Total & 4.925 .089 & $100,00 \%$ & & & \\
\hline Rumanía & 953.183 & 19,36 & 0,73 & 1,38 & 2,69 \\
\hline Marruecos & 770.735 & 15,65 & $-0,31$ & $-0,47$ & $-1,84$ \\
\hline Reino Unido & 275.817 & 5,60 & 1,22 & 2,25 & 3,87 \\
\hline Italia & 217.524 & 4,42 & 1,87 & 3,43 & 6,09 \\
\hline Ecuador & 192.404 & 3,91 & $-2,61$ & $-5,52$ & $-13,94$ \\
\hline China & 191.078 & 3,88 & 1,00 & 1,77 & 3,74 \\
\hline Bulgaria & 183.342 & 3,72 & 0,46 & 0,91 & 1,79 \\
\hline Alemania & 148.644 & 3,02 & 1,09 & 2,16 & 3,74 \\
\hline Portugal & 143.738 & 2,92 & 0,76 & 1,41 & 2,42 \\
\hline Colombia & 139.952 & 2,84 & $-2,71$ & $-5,43$ & $-13,81$ \\
\hline Francia & 124.131 & 2,52 & 1,84 & 3,42 & 6,45 \\
\hline Bolivia & 115.202 & 2,34 & -2.67 & $-5,11$ & $-12,27$ \\
\hline Polonia & 90.835 & 1,84 & 0,71 & 1,45 & 2,52 \\
\hline Ucrania & 82.067 & 1,67 & 0,69 & 1,13 & 2,13 \\
\hline Pakistán & 71.152 & 1,45 & 0,09 & 0,69 & 1,56 \\
\hline Resto de países & 1.224 .179 & 24,86 & 0,42 & 0,46 & $-1,10$ \\
\hline No consta & 1.106 & - & 1,28 & 1,56 & 5,53 \\
\hline
\end{tabular}

Fuente: Observatorio Permanente de la Inmigración "Extranjeros residentes en España, Principales resultados" (31 diciembre 2014). 
Una cuestión que se ve reflejada en uno de los fenómenos más acuciantes de estos procesos migratorios, las conocidas como remesas, que son interesantes de citar por lo que supone no sólo para el país al que son enviadas, sino para el país en el que se origina ese aporte económico. "Las remesas de los emigrantes se definen como la suma de las remesas de los trabajadores, la remuneración de los empleados y las transferencias de los emigrantes. Las remesas de los trabajadores, según lo definió el Fondo Monetario Internacional (FMI) en el Manual de Balanza de Pagos, son las transferencias privadas actuales de los trabajadores inmigrantes que se consideran residentes del país anfitrión realizadas a receptores en el país de origen de dichos trabajadores. Si los inmigrantes viven en el país anfitrión durante un año o más, se consideran residentes, independientemente de su estatus de inmigración. Si los inmigrantes llevan menos de un año viviendo en el país anfitrión, todos sus ingresos en el país anfitrión deberían clasificarse como remuneración de empleados" (Banco Mundial, 2011:9).

Un claro ejemplo, lo encontramos en Marruecos, considerado como uno de los países más dependientes de las remesas que recibe de sus emigrantes. En este sentido, la inmigración marroquí representa para España un factor socio económico importante que se ha visto marcado por una importante taza de afiliados a la seguridad social.

No obstante, más allá de estas cuestiones que describimos con un matiz positivo, la otra cara de la inmigración, la ilegal o clandestina, alcanza cifras desorbitadas y consecuencias negativas tanto para los propios inmigrantes, por las condiciones de vulnerabilidad y desamparo, como por los propios países receptores, por la falta de recursos para atender adecuadamente la desproporcionada situación en las que se encuentran, en ocasiones, los territorios fronterizos.

En este sentido, si analizamos estos procesos migratorios ilegales, en el caso de España, podemos observar como el Estrecho de Gibraltar (Fernández Alles, 2011) se ha caracterizado por ser la vía más utilizada, al representar un recorrido fácil y corto en el que las pateras se convierten en protagonistas de este tránsito. No obstante, la actuación combinada de las autoridades marroquíes y españolas ha facilitado en los últimos años, un enorme control sobre la zona, lo que ha conllevado la búsqueda de nuevas vías en cayucos desde Mauritania hasta Libia, pasando por Argelia o Túnez con destino a Canarias o Italia. Rutas migratorias de largo recorrido y mucho más peligrosas que aunque no son las que aportan las cifras elevadas, sin duda, son las más mediatizadas por los dramas que generan.

Los datos más recientes del fenómeno migratorio hacen previsible que los movimientos migratorios se mantengan y que la necesidad de trabajos en algunos sectores siga aumentando en los próximos años. Este crecimiento de la presión migratoria supone, al mismo tiempo, un crecimiento de los flujos clandestinos que utilizan las redes de tráfico de personas para los que España no solo es un destino, sino también, un lugar de tránsito.

En la actualidad, la inmigración ilegal representa un gran problema para los países de acogida. En el caso de España e Italia principalmente, las redes clandestinas toman el relevo de los circuitos legales. Cuestiones que nos llevan a reflexionar sobre las cuestiones que fomentan estas migraciones ilegales; la creación de grupos o mafias, el resultado de políticas sociales antidemocráticas de los países emisores de la emigración ilegal, el resultado de la política de cierre de fronteras adoptada por los países potentes como Europa y América, o el reparto injusto de la riqueza a nivel mundial y de economía desigual a nivel transfronterizo (ej.: España-Marruecos, Estados Unidos-Méjico, ...). No obstante, según el Informe Anual de Políticas de Inmigración y Asilo (Red Europea de Migraciones, 2011: 33) en lo referente a la inmigración irregular en España, los datos apuntan a una considerable reducción de la llegada de inmigrantes en situación irregular en la última década. 
Dicha caída es muy significativa en el caso de las Islas Canarias. Junto a la disminución en las llegadas de irregulares hay que contemplar el esfuerzo español por cumplir con la Directiva de Retorno 54 y el resto de obligaciones europeas en la materia (por ejemplo, la aplicación efectiva de la Directiva de sanciones a empleadores por contratar inmigrantes irregulares 55, etc.). La disminución en las cifras de inmigración irregular en España es consecuencia en buena manera del refuerzo de los recursos humanos y materiales disponibles (Moreno, 2011) a tal efecto (en línea con el cumplimiento de los compromisos europeos en la materia que se estudiarán a continuación en este informe), así como también de la creciente colaboración entre el Gobierno español, los países africanos y la Agencia FRONTEX en el control de la frontera externa y la prevención de la inmigración irregular.

\section{ANTECEDENTES E INCIDENCIA DE LA EMIGRACIÓN EN MARRUECOS}

El fenómeno de las migraciones, y sobre todo las migraciones ilegales, seguirán ocupando un lugar prioritario en el debate político y social de los países europeos que se ven afectados directa e indirectamente por esta situación. En el caso de Marruecos, merece realizar una reflexión, en torno a los diferentes factores y causas que envuelven esta situación; su ubicación geográfica y carácter fronterizo le colocan en una situación de continua tensión sociopolítica ante el fenómeno de las migraciones. Dadas las actuales condiciones de vida de los países subsaharianos, los flujos migratorios continuarán hacia el Norte de Marruecos que al unirse a los flujos migratorios nacionales, generarán una enorme demanda migratoria que desbordará las posibilidades legales y aumentará progresivamente la generación de mafias ilegales. Las rutas alternativas, como la generada entre Mauritania o Argelia y el sur de Marruecos, solo contribuyen a diversificar las alternativas, colocando a la Unión Europea en una complicada tesitura.

En el ámbito de lo social, podemos decir que es un fenómeno transocial que afecta a todas las clases en Marruecos. La tendencia afecta a todos los colectivos sociales marroquíes, si bien cada clase social da lugar a circunstancias muy distintas con perfiles migratorios particulares, la amplia gama que ofrecen los contextos sociales del emigrante va desde el universitario que busca mejorar su calificación en el empleo que puede ofrecerle Europa, hasta el joven sin estudios que se lanza a las vías ilegales.

$\mathrm{Su}$ proximidad con la Unión Europea (Fernández Alles, 2010), condiciona significativamente su relación con esta, de la que recibe importantes inversiones. De esta forma, las dificultades que soporta la economía marroquí se ven levemente beneficiadas por la colaboración del potencial vecino mediterráneo. En Marruecos, la dependencia de la agricultura y la economía sumergida, así como la inexistencia de un tejido industrial sólido reclaman la aportación de una Europa que es también actor interesado en el equilibro de su zona geográfica de mayor influencia.

En relación a las cuestiones de género, la sociedad marroquí, en la línea de los países musulmanes, marca estrictamente las diferencias entre los roles de mujeres y hombres, las cuales se ven reflejadas en los roles migratorios. En este sentido, podemos comprobar como las familias animan, con diferencia, a la emigración de los varones, por detrimento de las mujeres. No obstante, a partir de la aprobación de la Mudawana (código de familia marroquí) en 2004, (o Código de la Familia Marroquí, Ley n 70.03 promulgada por el DAHIR $\mathrm{N}^{\circ} 1.04 .22$ del 3 de febrero de 2004) después de una gran polémica entre los grupos conservadores y los progresistas en Marruecos, se garantizan mayores derechos para las 
mujeres, como la posibilidad para ellas de pedir el divorcio con nuevos argumentos, el aumento de los importes de las pensiones que el hombre debe pagar a su esposa después de la separación, la supresión de la figura del tutor para la mujer, el aumento de la edad legal para el matrimonio de 16 a 18 años y, lo que es especialmente importante, el haber puesto obstáculos con el fin de limitar y dificultar la práctica de la poligamia.

De esta forma, si el proyecto migratorio finalmente se lleva a cabo, es más usual entre los hombres, utilizar las vías ilegales para cruzar el Estrecho, y entre las mujeres, el matrimonio, los procesos de reagrupación familiar o los contratos de trabajo. La emigración de la mujer está generalmente vinculada a la de su grupo familiar, mientras el hombre es más propenso a lanzarse a la aventura individualmente. Recordemos la importancia que tiene en la cultura musulmana que la mujer dedique horas al cuidado de su casa y su familia, mientras que las expectativas sobre el hombre, implican que sea un buen proveedor de recursos al hogar.

En lo que respecta a la infancia, la ausencia de unas políticas sociales coherentes y eficaces que den cobertura a la infancia, está generando que 550.000 menores de menos de 15 años ( $80 \%$ en zonas rurales) trabajen en sectores como la agricultura, la confección textil, de aprendices en garajes, artesanía, trabajo doméstico, trabajos en la calle, servicio doméstico, etc., lo que hace imprescindible fortalecer las políticas sociales marroquíes que repercuten en la infancia y en la juventud (AECI, 2008: 11-12).

En este sentido, cabe destacar la brecha de género que se produce, que incide gravemente en las niñas, las cuales trabajan en condiciones precarias y en muchos casos sufren violencia, explotación sexual y maltrato por parte de las familias que las contratan. Prácticas que más allá de ser conocidas, no se denuncian lo suficiente, por miedo, así como por la ignorancia de los padres. Por otro lado, señalar también la situación de las niñas en las zonas rurales, que padecen numerosos problemas en lo que se refiere a la escolarización en la escuela primaria y la inexistente educación preescolar, comenzando a trabajar en el campo con edades muy tempranas, siendo víctimas de explotación en las ciudades como "petites-bonnes" (termino que se utiliza para denominar a las niñas que trabajan en el servicio doméstico).

Otro fenómeno preocupante es la migración de menores no acompañados. En España, la mayoría de los menores que emigran sin familias son de nacionalidad marroquí. Si bien es importante analizar cómo afecta en Marruecos la situación de la emigración, es primordial abordar los casos de emigraciones ilegales de menores, lo que en España se llama "menores ilegales no acompañados". Este fenómeno que es considerado como el último eslabón de una compleja y preocupante realidad social marroquí, está relacionado con diversos factores como: la desprotección social, una creciente feminización de la inmigración, una tasa de abandono escolar elevada entre los jóvenes, y una incorporación precoz al mundo laboral en condiciones precarias. Este panorama es el reflejo de la ausencia de una política integral de protección de la infancia, a pesar de los avances sociales. Marruecos ratificó la Convención de Los Derechos del Niño en 1993, y a través de La Mudawana integró el derecho de la infancia y la responsabilidad de los padres y del Estado en la protección del menor. Otro asunto importante que modificó la Mudawana es la acogida del menor (kafala) considerada como acción humanitaria que consiste en el acogimiento en una familia de un menor indigente, con el fin de educarlo y de ocuparse de él material y moralmente como si fuera su propio hijo, sin que ello produzca efectos sobre su filiación, de manera que el menor no rompa sus vínculos con su familia de origen.

El menor ve en la inmigración la única salida para ganarse la vida. Esta idea es afianzada por la falta de perspectivas de futuro de sus mayores -hayan estudiado o no-, y por la imagen de éxito social que transmiten los inmigrantes que regresan de vacaciones al país. 


\section{METODOLOGÍA Y MÉTODOS}

Hemos participado en la realización de un estudio (González Ferrera, 2008), como una aproximación al conocimiento de los movimientos migratorios recientes procedentes de Marruecos a través del Estrecho de Gibraltar, para tratar de conocer las tendencias y los problemas.

Para ello se han desarrollado dos investigaciones paralelas y complementarias. De una parte, el análisis de fuentes secundarias, sobre todo de tipo cuantitativo, que permite tener una visión general del fenómeno migratorio.

La otra parte del estudio se ha realizado con una metodología cualitativa. Se han realizado en total 81 entrevistas en profundidad e historias de vida a expertos en el tema (38 entrevistas: 22 en Andalucía y 13 en el norte de Marruecos) y a inmigrantes en situaciones migratorias y con características personales diversas (varones y mujeres, diversas edades, oriundos de Marruecos, Malí, Argelia, Costa de Marfil, Camerún, Liberia, Nigeria, Guinea Conakry, Senegal). Se han recogido las voces de inmigrantes adultos residentes desde hace años en Andalucía Sur, integrados en sus barrios y ciudades, hasta jóvenes recién llegados residiendo en instituciones de acogida (21 entrevistas). También a algunos de los que esperan en Marruecos, que han intentado llegar y no lo han conseguido aún, pero no abandonan un proyecto que da sentido a su vida, así como a personas que habiendo venido han vuelto, ya sea porque no les fue bien, ya sea porque fueron devueltos (22 entrevistas).

El objetivo es dar la voz a los propios inmigrantes o sus representantes y a miembros de organizaciones que trabajan con ellos, para conseguir su integración social en Andalucía. Con los discursos de estas personas hemos elaborado un único pero muy variado discurso que, más allá de los matices que han introducido los entrevistados, configuran un texto coherente y lógico que refleja «el punto de vista de los otros», dándoles la palabra sin reinterpretarla, salvando expresiones originales para que se pueda escuchar su voz más auténtica.

\section{RESULTADOS}

Analizar las características de las migraciones ilegales, nos lleva a detenernos en los protagonistas de estos procesos, acercándonos a una serie de indicadores comunes que nos permiten entender en mayor profundidad las migraciones.

Por un lado, la procedencia. Tradicionalmente, las migraciones procedían principalmente de la ciudad, muy escasas eran las cifras de los inmigrantes de origen rural. La primera emigración era del campo a la ciudad, era una emigración interna al país. Además los que emigraban no solían ser los más pobres. Actualmente, son más los rurales o habitantes de pequeña aldeas los que emigran.

Los candidatos son originarios no solo de Marruecos, también de otros países del Magreb o de África subsahariana. A veces tienen que atravesar varios países para llegar al Estrecho, exceptuando el caso marroquí. Posteriormente intentan acceder a España. Desde el año 2002, las migraciones por el Estrecho de origen marroquí están retrocediendo, mientras que la que procede de los países sub-saharianos está en constante aumento (desde el 2004 se duplicado esta tendencia, según datos del Ministerio del Interior marroquí).

Por otra parte, es interesante analizar el factor o los factores de motivan estos proyectos migratorios. En relación a las motivaciones, encontramos que las económicas, son las que 
impulsan masivamente a la gente a salir de su país, aunque, las razones también pueden ser de otra índole como huir de conflictos armados o de un clima social hostil o por el simple hecho de tener algún referente cercano que haya iniciado su proyecto migratorio.

En relación a la perspectiva de género, si bien en un principio, los emigrantes presentaban un perfil casi exclusivamente masculino, los movimientos migratorios están cambiando, y cada vez son más las mujeres que intentan la aventura legal o ilegalmente migrando a otros países, desde los cuales poder mantener económicamente a sus familias.

Un factor como la edad, también proporciona interesantes datos. Cada vez son más los jóvenes y menores (12-15 años) no acompañados que emigran clandestinamente sobre todo a España. Lo hacen escondidos en coches, autocares, contenedores, camiones, ... a menudo con la complicidad y el apoyo de los padres. En Marruecos, muchos jóvenes desamparados rondan por el puerto de Tánger con la esperanza de encontrar el modo de cruzar el Estrecho y, una vez en España, son considerados como menores inmigrantes no acompañados.

Finalmente, hacemos referencia al nivel de formación. En lo que concierne a la preparación formativa o al nivel de enseñanza cursado, la población migrante en su mayoría se ha identificado como población analfabeta y sin ningún nivel de instrucción. No obstante, cada vez son más los migrantes instruidos (bachiller y universitarios) y con una formación profesional cada vez más especializada (técnicos o ingenieros). En el caso de Marruecos, se trata de jóvenes diplomados que, frustrados por las nulas perspectivas de encontrar trabajo en su país, optan por buscar en la inmigración legal o ilegal, una salida o alternativa.

Los movimientos migratorios plantean nuevos desafíos en las relaciones internacionales de los países enfrentados a este fenómeno. La problemática que suscita exige una nueva visión de su incidencia sobre las economías, las sociedades y las políticas de los países de acogida y de origen. Es imprescindible realizar una revisión de la percepción y del papel que desempeñan los emigrantes como factor de desarrollo.

En relación a esto, el Pacto Europeo sobre Inmigración y asilo de 2008 (CUE, 2008: 5) señala que la inmigración legal debe obedecer a una voluntad doble, la del emigrante y la del país de acogida, con un objetivo de beneficio mutuo, instando a cada Estado miembro a decidir las condiciones de admisión en su territorio de los emigrantes legales y fijar en su caso, su número. Destacando la importancia de crear políticas que permitan un trato equitativo de los emigrantes y su integración armoniosa en la sociedad del país de acogida.

No obstante, la cuestión crucial del fenómeno de las migraciones es como resolver el problema de la inmigración ilegal. La repuesta a esta pregunta según los actores de nuestra encuesta pasa necesariamente por una reflexión profunda y una verdadera cooperación para el desarrollo entre Europa y África. Para su lucha contra la inmigración irregular, la UE cuenta con Frontex, La Agencia Europea para la Gestión de la Cooperación Operativa en las Fronteras Exteriores de los Estados miembros de la Unión o Frontex (de fronteras exteriores) es una agencia de la Unión Europea (UE), cuyo fin es mejorar la gestión integrada de las fronteras exteriores de los Estados miembros de la Unión. Su sede se encuentra en Varsovia. Mientras siga existiendo una enorme fractura económica y social entre una Europa opulenta y una África de miseria y de pobreza, seguirán existiendo los candidatos dispuestos a todo con tal de buscarse la vida en otro sitio. Europa tiene que considerar como socios a los países emisores de una inmigración no deseada por ella, y buscar conjuntamente los mecanismos y las políticas que les permita sentar las bases de una economía basada en la innovación, la investigación y el desarrollo tecnológico, único gaje para un desarrollo humano sostenible.

Los países Africanos tienen una gran responsabilidad en la desesperación social de sus países, desesperación que les empuja a arriesgar la vida por intentar alcanzar la otra orilla. Estas odiseas suicidarías tienen que cesar y para lograrlo los países africanos tienen la 
responsabilidad y la obligación de promover políticas que permitan crear las condiciones mínimas para una vida decente.

En el caso de Marruecos existe una voluntad de compromiso con la Unión Europea para buscar soluciones al problema de la inmigración ilegal. El país magrebí está colaborando activamente para frenar el flujo de inmigrantes subsaharianos (principalmente) que utilizan su territorio para sus proyectos migratorios. El acuerdo está funcionando bastante bien por el momento. Sin embargo, a pesar de los cambios importantes que se están produciendo en el país a todos los niveles, se consideran insuficientes, según algunos, demasiado lentos según otros, y no se dibuja en el horizonte una mejora en las perspectivas de futuro para una gran parte de la población marroquí joven y frustrada.

En este sentido, la sociedad marroquí, más allá del respaldo económico con el que cuenta, procedente de países de la Unión Europea, contempla problemáticos desequilibrios económicos con bajos salarios de la mayor parte de la población, un elevado desempleo (19\% de la población activa), una enorme dependencia de la agricultura, así como una economía sumergida difícil de controlar, con escasas coberturas sociales, como por ejemplo la inexistencia de desempleo. Por otro lado, encontramos una profundas desigualdades sociales que son el reflejo de que aproximadamente el $20 \%$ de la población gestione el $80 \%$ de los recursos. En relación a la población joven, las cifras desvelan altas tasas de natalidad y mortalidad, así como escasas medidas de contracepción y un importante predominio cultural de la familia numerosa sobre todo entre la población rural, un $45 \%$ de la población total (OMS, 2013:54).

\section{CONCLUSIONES}

El emigrante en Marruecos está tomando, cada vez más, un perfil transocial. Los perfiles migratorios (“...La diversidad de perfiles migratorios por su procedencia, destino, edad, género, nivel de instrucción hace del fenómeno migratorio un proceso complejo que no responde a un único modelo de comportamiento...." (Nieto, 2005), se han extendido muy notoriamente a las clases medias y altas. En este fenómeno ha resultado determinante el efecto llamada generado por personas del mismo nivel social que se han integrado en Europa logrando importantes progresos en sus carreras profesionales y en sus estudios. Estas circunstancias delatan las enormes deficiencias aún existentes en Marruecos en formación y empleo (González, 2006) a pesar de los esfuerzos recientes del Rey Mohamed VI. La Unión Europea continuará siendo protagonista en el debate sobre la emigración y deberá tomar parte activa en el desarrollo del norte de África, si realmente pretende moderar los flujos migratorios actuales. El que fue gobierno de los veinticinco había mostrado en su Consejo del mes de octubre 2006, en la ciudad finlandesa de Lahtí, su propósito de poner punto y final a las regularizaciones masivas, con un contundente tirón de orejas al último Estado que apostó por ellas: el español. En 2009, más de 20.000 extranjeros en situación ilegal han sido regularizados por el Gobierno Sarkozy en Francia (Nations Press, 2009).

En este sentido, hay iniciativas interesantes, como la que se llevó a cabo en el Consejo Europeo del 20 de octubre de 2006; la creación de agencias de empleo europeas en terceros países para compensar el freno en las políticas regularizadoras. Cataluña fue precursora, en este sentido, incentivando a las empresas catalanas para abrir despachos de asesoramiento o de contratación directa en Marruecos ("Garrigues abre un despacho en Casablanca para asesorar las empresas españolas que inviertan en Marruecos”), o con la apertura de una 
oficina de empleo en Tánger para contratar trabajadores marroquíes que quieran venir a Cataluña y ayudar a las empresas catalanas erradicadas en tierra marroquí a encontrar mano de obra, que en su mayoría son del sector textil. Abrió sus puertas el 2 de mayo 2006 y tuvo que cerrar a las dos semanas de su inauguración ante el alud de demandas venidos de toda parte del país (Libertad Digital, 2006).

Esta política está teniendo un éxito moderado hasta el momento con respeto a la disminución de la presión migratoria.

Estas acciones no serán suficientes, y son sólo un esbozo de la política que los Estados de la Unión Europea deberán aplicar a corto plazo. Pero, al menos, fue una propuesta esperanzadora que trajo el recuerdo de tiempos pasados en las migraciones europeas, en los que la mayoría de los trabajadores del sur de Europa que llegaban a países receptores como Alemania y Suiza, lo hacía con un contrato de trabajo bajo el brazo. En las décadas de los 50 y 60, la política migratoria en Europa acabó beneficiando tanto a los países de acogida como a los de origen. De esta forma el mercado de trabajo europeo se estabilizó y el Sur contribuyó a la dinamización industrial del Norte.

En el futuro del Mediterráneo será determinante enfocar las políticas de gestión de las migraciones conforme a las siguientes bases:

a) Hacia un cambio de perspectiva: la migración como intercambio, progreso y dignidad humana

Para afrontar el futuro de las políticas migratorias europeas resulta esencial asumir que los beneficios de las migraciones no sólo se dan en los países exportadores de mano de obra. Marruecos es uno de los países del mundo que más depende de las remesas de sus inmigrantes, estas representan cerca del 10\% del PIB y la Agricultura el 15\% del PIB (datos de la Oficina de Cambios, 2011). Históricamente estos beneficios se hacen también muy palpables en los países receptores. España ingresa casi el doble de lo que gasta por los inmigrantes según Rosa Aparicio Gómez (Aparicio Gómez, 2000).

El pasado reciente de los países europeos así lo demuestra. No obstante, debemos plantear las migraciones como un intercambio que beneficia a ambos bloques, genera progreso y estabilidad, si bien debemos entender que la recompensa no es la misma para unos y otros. En este sentido, Europa debe ingeniarse en conjugar los beneficios de las migraciones con algunos efectos perversos.

b) Aumento de la demanda de mano de obra en los países industrializados de Europa.

Esta circunstancia, unida a las carencias en la oferta de mano de obra en el norte de África, implica que tendremos que seguir conectándola con los flujos. La población marroquí, al igual que la mayor parte de África está soportando condiciones de infra salario. Sin embargo, el tejido empresarial europeo aún presenta algunas carencias para cubrir algunos puestos, especialmente, en el sector servicios y la agricultura. En el caso de Marruecos (Dirección de la Estadística, 2004) hay que destacar los desequilibrios siguientes: una renta per cápita 17 veces inferior a la de España, una economía que depende del sector primario muy inestable debido a los cambios climáticos, el paro que aumenta entre las mujeres y la población joven (más del 60\% de la población activa en paro tiene menos de 30 años), según el umbral de la pobreza (fijado por el Banco Mundial a leuro por persona y día) cerca de $19 \%$ de la población marroquí es pobre, el salario mínimo es cuatro veces inferior al de los países europeos.

Además, en caso de no haber contado con la mano de obra emigrante de los últimos 20 años, los salarios hubieran subido hasta un punto difícilmente soportable para las empresas y se hubiera complicado la existencia al consumidor por la subida del precio final. La opinión pública europea debe superar los momentos de crisis económica y de empleo que les hacen 
mirar con recelo a los emigrantes. Su mano de obra ha sido esencial en otros momentos difíciles.

c) Revitalización demográfica de países europeos con el apoyo natalista de los países del sur.

Este ha sido el caso de los países nórdicos, Francia, Reino Unido, Alemania, Holanda, Italia y, posteriormente, España. Los demógrafos europeos encendieron la luz roja sobre el problema del envejecimiento en la década de los 80 . Según los redactores del "libro azul" (Grenis, 1989), profético en algunos aspectos: "de los 170 millones de ribereños de aquí al año 2025, 68\% habrán nacido en un país árabe, $22 \%$ en Turquía y solamente $10 \%$ en Europa”.

Los rasgos sociológicos de estas sociedades les impedían levantar su población por si solas. Sin duda, la inmigración ha sido determinante para que un país como España donde se incrementado considerablemente la tasa de natalidad.

d) Equilibro en los niveles de renta y de prestaciones sociales en ambas orillas del Mediterráneo.

Las mismas razones demográficas y económicas, anteriormente explicadas, obligan a la vieja Europa a poner sus límites al fenómeno migratorio. La Unión Europea tiene cada vez más clara la importancia de la emigración africana, en dos líneas opuestas: hay que detener la inmigración clandestina, pero también hay que dar entrada a un contingente de personas totalmente necesarias para mantener el crecimiento actual. Por ahora no existe una política común, cada país actúa por su cuenta. De momento se dedican a controlar lo mejor posible sus fronteras y a exigir a Libia, Marruecos y Argelia el control de la migración.

Si está claro que el espacio físico es limitado, debemos identificar el entorno Mediterráneo como un ecosistema político que hay que mantener en equilibrio: todo está muy cerca como para tratar de verlo de forma aislada. Las civilizaciones antiguas que lucharon por el control del Mare Nostrum ya observaron la necesidad de tratarlo como un área geográfica interdependiente. La Unión Europea, por intereses propios y ajenos, debe potenciar el desarrollo económico del Norte de África aumentando, aún más, sus coberturas en cooperación.

e) Erradicar la emigración ilegal y actuar sobre las causas que la originan y la sustentan

Los países de la Unión Europea deben ser estrictos en el control de los ilegales y lograr la cooperación de los gobiernos africanos para evitar que proliferen las redes que desestabilizan el ecosistema social y, en algunos casos, ponen en peligro a sus ciudadanos. Si bien, la labor fundamental de los políticos de ambos continentes está en canalizar estos intereses hacia nuevas oportunidades de emigración legal, u ofrecer alternativas solventes en los destinos de origen. Moratinos ha hablado de la cumbre sobre inmigración y desarrollo que tuvo lugar en Rabat en julio pasado y que reunió 57 países de África y Europa "como un nuevo modelo de abordar el fenómeno migratorio más pragmático y eficaz, a partir de la corresponsabilidad de los países de origen, de tránsito y de destino".

A pesar de las buenas intenciones manifestadas en esta cumbre, preocupa el hecho que todo se quede en una mera declaración de buenas intenciones, en la medida que no se han asumido compromisos concretos con calendarización.

Las regularizaciones masivas, tan discutidas en los tiempos que corren, sólo solucionan el problema de algunos de los ilegales ya desplazados, pero implican un aumento del efecto llamada en los países de origen, alimentando el papel de las mafias y generando nuevos riesgos.

Hay que actuar sobre las causas que generan el fenómeno de la inmigración ilegal, en el caso de la migración marroquí, se enmarca en una problemática global que interpela a los gobiernos de Marruecos como a los de los países de la Unión Europea. 
En primer lugar, hay que romper con los esquemas vinculados al síndrome de la seguridad y de los riesgos relacionados con la inmigración y apostar por un enfoque preventivo orientado hacia una política realista porque basada en una necesidad.

Sería interesante que la política de cooperación ayudara a la estabilización territorial de la población, porque es una manera de frenar la emigración interna y así frenar los flujos migratorios hacia Europa. Para ello se necesita programas de cooperación que dinamicen la economía del país (o de los territorios desde una perspectiva de cooperación descentralizada) de origen con el fin de crear empleo y en los cuales haya repercusión a efectos multiplicador.

f) Ineficacia de pactos y actuaciones entre la Unión Europea y los países emisores.

Existe un sentimiento generalizado entre la población marroquí de que las políticas europeas, o españolas en materia de cooperación y de apoyo al desarrollo no van encaminadas hacia un desarrollo total de los países emisores de la inmigración, y que sirven más sus propios interés. Lo más urgente según entendemos es hacer un inventario de la memoria y potenciar el intercambio de tecnología, creando centros mixtos para la valorización y revalorización de las culturas de ambos países y para la promoción de la investigación científica. También es importante potenciar la transferencia de tecnologías a través de los centros, en particular andaluces, de Innovación tecnológica. El objetivo a medio y largo plazo es edificar un verdadero proyecto de sociedad con todos sus componentes y no limitarse a solo algunos aspectos limitativos de la cooperación de una $u$ otra cultura.

g) Mayor compromiso de los gobiernos africanos para contrarrestar las migraciones masivas e ilegales

Europa ha sido un antiguo colonizador en los países africanos. Con el tiempo, estos han accedido a la independencia política pero siguen dependiendo de Europa a nivel económico y social. Es por ello que Europa debe tomar en consideración el pasado de su relación con África, y apostar por estrategias socio económicas que permitan dar a los países africanos la posibilidad de mejorar sus realidades.

Por otro lado, a pesar de que los países africanos colaboran en mayor o menor medida en la limitación de la inmigración ilegal, el mercado de las mafias que se benefician de estos procesos es importante, lo que nos lleva a reflexionar sobre la actual crisis migratoria.

En el caso particular de Marruecos, dada la diversidad de recursos con los que cuenta, es necesario instar a sus administradores a una gestión responsable y equitativa, generando políticas sociales que garanticen una mayor calidad de vida de su población. Fortaleciendo así un capital humano que revierta sobre su propio territorio, favoreciendo un mayor desarrollo humano en el país.

\section{BIBLIOGRAFÍA}

ABC (2006). "La Generalitat abrirá en Tánger su primera oficina de captación laboral en origen”, en $A B C$, http://www.abc.es/hemeroteca/historico-18-04-2006/abc/Catalunya/la-generalitat-abrira-en-tanger -su-primera-oficina-de-captacion-laboral-en-origen_1421185947802.html\# [consulta 28/4/2015].

AECI (2008). Documento de Estrategia País 2005-2008 Cooperación española Marruecos, Agencia Española de Cooperación Internacional. Madrid: Edita AECI.

APARICIO GÓMEZ, R. (2000). "El impacto económico de la inmigración: costos para el Estado y movimiento de consumo y salarios". II Congreso sobre la Inmigración en España: Las Migraciones Internacionales en el Cambio de Siglo. Madrid, http://sirio.ua.es/documentos/pdf/inmigracion econo mia/el\%20impacto\%20economico\%20de\%20la\%20inmigracion.pdf, pp. 1-40 [consulta 14/4/2015]. 
BANCO MUNDIAL (2011). Datos sobre migración y remesas 2011, en http://siteresources.worldbank. org/INTPROSPECTS/Resources/334934-1110315015165/Factbook2011Spanish.pdf, p.3 [consulta 18/4/2015].

BENAMAR, J. (2012). "Contratación de inmigrantes marroquíes, oportunidades para las PYMEs andaluzas". Revista Cámara de Comercio de Sevilla, pp. 22-23.

CHECA, F., et al. (2014). Los inmigrados marroquies en Andalucía, una investigación necesaria. Almería: CEMyRI, Universidad de Almería.

CHECA, F., et al. (2000). Convivencia entre culturas: El fenómeno migratorio en España. Sevilla: Signatura Ediciones de Andalucía.

CUE (2008). Pacto Europeo sobre inmigración y asilo. Bruselas: Consejo de la Unión Europea, CUE. DIRECCION DE LA ESTADÍSTICA (2004). Recensement général de la population et de l'habitat, Rabat (Marruecos). http://www.hcp.ma/Recensement-general-de-la-population-et-de-l-habitat-2004_ a633.html [consulta 9/5/2015].

EGEA JIMÉNEZ, C. (2005). "La inmigración actual en Andalucía (1997-2001)". Geo Crítica / Scripta Nova. Revista electrónica de geografía y ciencias sociales, Vol. IX, núm. 192, 1 de julio de 2005, en http://www.ub.edu/geocrit/sn/sn-192.htm [consulta 14/10/2014].

EL ECONOMISTA (2008). Economía/Legal.-Garrigues refuerza su presencia en Marruecos con una nueva oficina en Tánger, en http://www.eleconomista.es/legislacion/noticias/885640/11/08/EconomiaLegal-Garrigues-refuerza-su-presencia-en-Marruecos-con-una-nueva-oficina-en-Tanger.html\#.Kku8Ib Tbwp0v8ZW [consulta 28/04/2015].

FERNÁNDEZ ALLES, J. y BENAMAR, J. (2011). Estudios sobre gobierno y desarrollo en el contexto del Estrecho de Gibraltar. Proyecto PCI AECID C/023894/09. Tánger: Editions Ifzarne.

FERNÁNDEZ ALLES, J. y BENAMAR, J. (2010). La gestión pública fronteriza en el Estrecho de Gibraltar, interacción, competencia y complementariedad. Proyecto PCI AECID B/017487/08. Tánger: Editions Ifzarne.

GARCÍA-CALABRÉS COBO, F. (2004). La extranjera, estudio de la inmigración femenina en España. Córdoba: Dirección General de Coordinación de Políticas Migratorias, Junta de Andalucía.

GARCIA RODRIGUEZ, J. (1994). "Análisis del factor sociocultural-religioso", en http://dialnet.uni rioja.es/servlet/articulo?codigo=2779135, 141-153 [consulta 14/10/2014].

GÓMEZ SOTA, F. (2004). Imágenes cruzadas. Percepciones españolas de la inmigración marroquí en la Comunidad de Madrid. Madrid, UNED.

GONZÁLEZ FERRERA, G.; BENAMAR, J., et al. (2008). Análisis de los flujos migratorios entre el Norte de África y el Sur de Andalucía. Sevilla: Junta de Andalucía.

GONZÁLEZ FERRERA, G.; BENAMAR, J., et al. (2006). Estudio sobre la situación de las mujeres a ambos lados del Estrecho de Gibraltar. Sevilla: Instituto Andaluz de la Mujer.

HERNANDO DE LARRAMENDI, M. y MAÑÉ, A. (2009). La política exterior española hacia el Magreb: actores e interés. Barcelona, Ariel.

HILAL, L.; VALLEJO PEÑA, F. A., et al. (2009). La identidad de la mujer marroquí actual. Tánger, PCI AECID A/014281/07 Tánger: Editions Ifzarne.

KHACHANI, M. (2009). "The impact of migration on the Moroccan economy". Journal of Ethnic and Migration Studies, 35 (10): 1609-1621.

LA COMBA, J. (2004). Migraciones y desarrollo en Marruecos. Madrid: La Catarata.

LIBERTAD DIGITAL (2006). "La Generalidad abre un INEM en Tánger y tiene que cerrar a las dos semanas ante la avalancha de inmigrantes", en http://www.libertaddigital.com/sociedad/la-generalidadabre-un-inem-en-tanger-y-tiene-que-cerrar-a-las-dos-semanas-ante-la-avalancha-de-inmigrantes-

1276279301/ [consulta 28/04/2015].

MAHÍA, R. (2005). El efecto de la inmigración Económica en el mercado español: Cifras básicas y reflexiones analíticas. Madrid: UAM.

MORENO FUENTES, F. J. y BRUQUETAS CALLEJO, M. (2011). Inmigración y estado de bienestar en España. Barcelona: Colección Estudios Sociales n 31 , Obra Social la Caixa.

NIETO, J. A.; RODRÍGUEZ, V. y JIMÉNEZ, F. (2005). "La inmigración actual en Andalucía (19972001)". Geo Crítica / Scripta Nova. Revista electrónica de geografía y ciencias sociales. OBSERVATORIO PERMANENTE DE LA INMIGRACIÓN (2014). Extranjeros residentes en 
España, principales resultados. Madrid: Publicaciones del Ministerio de Empleo y Asuntos Sociales, en http://extranjeros.empleo.gob.es/es/Estadisticas/operaciones/con-certificado/201406/Residentes_Princi pales_Resultados_30062014.pdf[consulta 2/9/2014].

OIM (2014). La Constitución de la OIM y otros textos fundamentales de sus órganos rectores. Ginebra: Organización Internacional para las Migraciones.

OMS (2013). Stratégie de Coopération OMS-Maroc 2008-2013. Bureau régionale de la Méditerranée Orientale, Le Caire, Edita OMS.

NATIONS PRESS (2009). "Le gouvernement de Sarkozy a régularisé 20.000 clandestins cette année", en http://www.nationspresse.info/non-classe/le-gouvernement-de-sarkozy-a-regularise-20-000-clandesti ns-cette-annee [consulta 24/03/2015].

RED EUROPEA DE MIGRACIONES (2011). Informe anual de políticas de inmigración y asilo. Madrid: Edita OPI.

SEBASTIÁN, M. (2006). Inmigración y economía española: 1996-2006. Madrid: Oficina Económica del Presidente.

\section{Breve currículo:}

\section{Jamal Benamar}

Catedrático de la Universidad Abdelmalek Essaãdi de Tánger, Marruecos. Director del Departamento de Economía y Gestión. Director del Grupo de Investigación en Economía y Territorio de la Facultad. Experto en Cooperación Internacional y Desarrollo Sostenible para la Universidad. Miembro del Consejo de la Facultad y de sus comisiones Científica y Pedagógica. Co-coordinador mediterráneo de proyectos con universidades españolas, desde más de una década, entre los cuales Aula Universitario del Estrecho, AECI, INTERREG, POCTEFEX, Art-Gold Marruecos o Junta de Andalucía. Autor y coautor de numerosos trabajos publicados sobre las migraciones o la condición de la mujer en el Norte de Marruecos.

\section{Noelia Melero Aguilar}

Doctora por la Universidad de Sevilla. Miembro del Grupo de Investigación "Educación de personas adultas y desarrollo". Profesora del departamento de Teoría e Historia de la Educación y Pedagogía Social de la Universidad de Sevilla. Coordinadora y docente de diversos postgrados en Género, Desarrollo y Cooperación Internacional, en la Universidad de Sevilla, Universidad de Cádiz, Universidad Abdelmalek Essaãdi de Tánger, Universidad de La Habana, Universidad de Cartagena de Indias y FLACSO-Argentina. Investigadora en Proyectos de Cooperación Interuniversitaria (PCI) del Ministerio de Asuntos Exteriores y Cooperación (España), y en Proyectos de Investigación de I+D+i del Ministerio de Economía y Competitividad (España). 